\title{
The role of endothelin-1 in the pathogenesis of idiopathic pulmonary fibrosis
}

\author{
Jeffrey J. Swigris, D.O., M.S. [Assistant Professor of Medicine] and \\ Interstitial Lung Disease Program, National Jewish Health, Denver, Colorado \\ Kevin K. Brown, M.D. [Director] \\ Interstitial Lung Disease Program, National Jewish Health, Denver, Colorado
}

\begin{abstract}
The endothelin system participates in a number of critical biologic pathways, including normal wound healing. In addition, emerging basic science, animal and human data all suggest that endothelin-1 (ET-1) is a potentially important contributor in the pathobiology of fibrosing disorders, including those that affect the lung. For example, ET-1 drives fibroblast activation, proliferation, as well as differentiation into myofibroblasts - processes that lead to excessive collagen deposition. Patients with idiopathic pulmonary fibrosis (IPF) have increased levels of ET-1 in both their bronchoalveolar lavage fluid and lung tissue. Beyond this, rodent models suggest that endothelin receptor antagonists can limit bleomycin-induced lung fibrosis. This suggests a biologic rationale for the blockade of ET-1 to limit the evolution of lung fibrosis in humans. Initial results from a trial examining the efficacy of a dual endothelin receptor antagonist suggest that this approach may delay disease progression in a subset of patients with IPF.
\end{abstract}

\section{Molecular Biology of the Endothelin System}

The endothelin system produces a diverse range of biological effects in a variety of tissues throughout the body. Among its better-known effects is the regulation of both airway and blood vessel tone. Consisting of three ligands, two membrane-bound activating proteases, and two receptors (Figure 1), this system has also been shown to have a significant effect on wound healing. All three of the ligands (ET-1, -2, and -3) are synthesized from a large precursor molecule, preproendothelin. These preproendothelins are processed by specific, furin-like proteases into biologically inactive 38 -amino acid moieties, proendothelins or big endothelins. ${ }^{1}$ Each of the three big endothelins (big ET-1, -2, and -3) is indiscriminately cleaved by one of two membrane-bound metalloproteinases, endothelin converting enzyme (ECE)-1 or -2, to produce its corresponding 21-amino acid, metabolically active endothelin peptide.2, 3 Both ECE-1 and -2 preferentially cleave big ET-1, the most abundant of the three endothelins, whose levels are highest in the lung. Endothelin-2 and -3 are expressed by intestinal epithelial cells, while ET-3 is also expressed by brain neurons and renal tubular cells.4.5

In the lung, fibroblasts, endothelial cells, alveolar macrophages, epithelial cells, and polymorphonuclear leukocytes all secrete ET-1. ${ }^{6-9}$ Endothelin-1 is not stored. Its regulation takes place at the level of gene expression and protein synthesis; both can be affected by a host of factors, including angiotensin II and thrombin, as well as mechanical factors like shear stress. ${ }^{3}$ Eighty percent of ET-1 synthesized in lung endothelial or epithelial cells is transported to the basolateral cell pole via intracellular vesicles ${ }^{10}$ and secreted through the basolateral membrane.

Author Correspondence: Jeffrey J. Swigris, MD, Interstitial Lung Disease Program, National Jewish Health, 1400 Jackson Street, Denver, Colorado 80206, Phone: (303) 398-1621, swigrisj@njc.org. 
Here, it acts on nearby smooth muscle cells and other interstitial constituents via autocrine and paracrine mechanisms. ${ }^{1,3,11}$ Not surprisingly, concentrations of ET-1 within vessel walls are over 100 times their concentrations within the plasma. ${ }^{2}$ While peptide secreted into vessel lumens can act at distant sites as a hormone, under normal conditions, ET-1 plasma concentrations are two orders of magnitude below the pharmacological threshold. ${ }^{2}$

There are three endothelin-specific receptors, but only two- $-\mathrm{ET}_{\mathrm{A}}$ and $\mathrm{ET}_{\mathrm{B}}-$ have been cloned in humans. ${ }^{12,13}$ Endothelin-1 has greater affinity for $\mathrm{ET}_{\mathrm{A}}$ than do the other two endothelins, while each of the ligands has equal affinity for $\mathrm{ET}_{\mathrm{B}}$. These receptors are located on a number of cell types and in a variety of organ systems throughout the body, including the pulmonary, nervous, cardiovascular, renal, and integumentary systems. In the lung, $\mathrm{ET}_{\mathrm{A}}$ receptors are found in greatest quantities on vascular and airway smooth muscle cells; Type B receptors are also found on smooth muscle cells but are predominantly located on endothelial cells, where $\mathrm{ET}_{\mathrm{A}}$ is not expressed. ${ }^{2,14,1512,13}$ In human bronchi, there are ten times more $\mathrm{ET}_{\mathrm{B}}$ receptors than $\mathrm{ET}_{\mathrm{A}}$ receptors. ${ }^{16,17}$

The initial, short-term response to an intravenous bolus of ET-1 is a decrease in vascular resistance, primarily mediated by the release of nitric oxide and prostacyclin from $\mathrm{ET}_{\mathrm{B}^{-}}$ stimulated endothelial cells.18, ${ }^{19}$ A subsequent and longer-lived (up to an hour) increase in

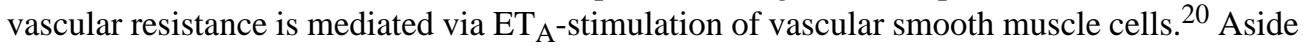
from its other activities, $\mathrm{ET}_{\mathrm{B}}$ also acts as a scavenger receptor, mediating ET-1 clearance from the circulation, primarily in the lung and, to a lesser degree, in the liver and kidney. ${ }^{21}$

\section{Normal Wound Healing, Fibrosis, and ET-1}

Normal wound healing involves a complex series of structural and biochemical events that give rise to new epithelium, blood vessels, and connective tissue. ${ }^{22}$ Study of these events in skin has yielded extensive information on normal healing, which is described as occurring in three main phases: inflammation, proliferation, and matrix formation with remodeling. ${ }^{23}$ In one of the earliest events in the inflammatory phase, the coagulation system is activated. Later in the inflammatory phase, macrophages take on a key role, synthesizing and releasing regulatory and growth factors. 24,25 .

One of the key occurrences in normal wound healing, whether in the lung, skin, or any other organ, is fibroblast migration into the wound bed. Once there, fibroblasts are driven to proliferate and express $\alpha$-smooth muscle actin, a key property of the myofibroblast phenotype. Fibroblasts, myofibroblasts, endothelial cells, macrophages, and other cells proliferate and embed themselves in a collection of collagen, fibrin, fibronectin, proteoglycans, and other molecules, which collectively comprise granulation tissue. Fibroblasts and myofibroblasts within the granulation tissue secrete extrecellular matrix (ECM), which consists of numerous components, including various proteins - of which collagen is the most abundant. The ECM provides attachment sites for cell surface receptors and serves as a reservoir for signaling factors. The ECM also gives healing tissue structural support; ${ }^{26}$ it has been called "nature's natural scaffold for...tissue reconstruction following injury"26 (Figure 2). Granulation tissue constituents are extremely metabolically active, and adequate blood flow is needed to support it. Thus, in conjunction with ECM formation, angiogenesis- the process of new blood vessel formation-occurs in this new tissue proliferation phase.

Through its contractile properties, the myofibroblast is primarily responsible for remodeling the ECM and giving it tensile strength. ${ }^{27}$ In normal wound healing, once the ECM is restored and remodeled appropriately, fibroblasts and myofibroblasts are down-regulated, cease collagen production, and undergo apoptosis; sound organ function then returns. ${ }^{28}$ During the inflammatory phase, through its effects on various cells, ET-1 is involved in normal wound 
healing: ET-1 can prime neutrophils ${ }^{29}$ and stimulate monocytes to produce a number of cytokines. ${ }^{30}$ Endothelin-1 also plays a role in the later phases of healing by stimulating fibroblast chemotaxis, ${ }^{31,32}$ proliferation, ${ }^{33}$ and procollagen formation. ${ }^{34,35}$

Accumulating evidence suggests that ET-1 is active in fibrogenesis. Although detailed descriptions of the intracellular mechanisms through which ET-1 mediates pro-fibrotic actions are beyond the scope of this review, some of the ways in which ET-1 participates in fibrogenesis are highlighted here. For example, one of the key features of fibrogenesis is abnormal persistence of the myofibroblast phenotype in healing tissue, which leads to high levels of matrix constituents (particularly collagen), exuberant ECM contraction, and ultimately, scar formation.36 ET-1 is one molecule that can induce resistance to apoptosis in lung fibroblasts - a process carried out via the pro-survival PI3/AKT signalling pathway.37 In certain tissues, ET-1 enhances the expression of the profibrotic moieties, fibronectin and connective tissue growth factor, and it reduces collagenase activity.38 Endothelin- 1 can act synergistically with a number of molecules known to be important in fibrogenesis, including transforming growth factor-beta (TGF- $\beta$ ), basic fibroblast growth factor, and platelet-derived growth factor to induce cellular transformation or replication. 3 For example, in endothelial cells, the potent fibrogenic cytokine TGF- $\beta$ induces ET-1 gene expression and protein release via direct transcriptional regulation of the ET-1 gene promoter.39 In cultured human lung fibroblasts, ET-1 induces expression of the myofibroblast phenotype-the collagen-producing machinery in IPF-31,38 effects that appear to be dependent on $\mathrm{ET}_{\mathrm{A}}$ but not $\mathrm{ET}_{\mathrm{B}} \cdot{ }^{38}$

\section{The Role of ET-1 in Lung Fibrosis: Animal Models}

Several investigators have examined the impact of the endothelin system on lung fibrosis. Transgenic mice with lung-specific overexpression of the human gene for ET-1 spontaneously develop chronic lung inflammation and fibrosis, and they develop perivascular and peribronchiolar accumulations of extracellular matrix proteins and large collections of CD4 positive mononuclear cells. Interestingly, pulmonary hypertension does not develop. ${ }^{40}$

Results of endothelin receptor antagonism on lung fibrosis have been contradictory. For example, Park and colleagues found that both ET-1 and ECE-1 immunoreactivity are increased in a rat model of bleomycin-induced pulmonary fibrosis and that a non-selective endothelin receptor antagonist reduced the amount of fibrosis. ${ }^{41}$ In contrast, Mutsaers and co-investigators found that neither an $\mathrm{ET}_{\mathrm{A}}$ selective nor a non-selective endothelin receptor antagonist altered bleomycin-induced collagen deposition in the rat. ${ }^{42}$

\section{The Role of ET-1 in Lung Fibrosis: Human Data}

The precise pathobiology of progressive lung fibrosis is unknown. The current hypothesis proposed for the development and progression of IPF is that it is an "epithelial-fibroblastic" disease. ${ }^{43}$ In this model, injured alveolar epithelial cells orchestrate the development of an actively profibrotic environment by producing pro-fibrotic cytokines such as TGF- $\beta$, tumor necrosis factor-alpha (TNF- $\alpha$ ), and ET-1. Within this environment, fibroblasts are chronically activated, resulting in the development of myofibroblasts, excessive production of collagen and ECM, and dysregulated tissue repair. ${ }^{44}$

A number of studies have evaluated the role of ET-1 in human pulmonary fibrosis. Additional data from studies examining biological samples from subjects with scleroderma (SSc) and scleroderma-associated interstitial lung disease (SSc-ILD) also exist. In fact, the first clinical evidence suggesting that ET-1 played an important role in tissue fibrosis came from patients with SSc.45 In these patients, ET-1 expression is increased in the skin46 and lung.47 Although most patients with SSc-ILD have a nonspecific interstitial pneumonia (NSIP) rather than usual interstitial pneumonia (UIP) pathologic pattern of lung injury (the pathologic correlate of IPF), 
data from these patients provide potentially important insights into the role of ET-1 in fibrotic lung disease, including IPF.

In patients with SSc-ILD, ET-1 levels are increased in bronchoalveolar lavage (BAL) fluid, 47 and nearly half of the fibroblast mitogenic activity of the BAL fluid in these patients is due to ET-1.33 Increased levels of ET-1, when compared with levels in healthy controls, are also found in the exhaled breath condensate of subjects with either idiopathic NSIP or SSc-ILD. 48 Further, ET-1 expression is increased in the lungs of subjects with SSc and related pulmonary fibrosis but without clinical evidence of pulmonary hypertension; while ET-1 expression is absent in normal control lung. 33 Shi-Wen and colleagues showed that fibroblasts cultured from the explanted lungs of SSc-ILD patients had enhanced ET-1 expression and that expression of alpha-smooth muscle actin (and other contractile proteins) could be reduced by antagonizing endogenous ET-1 signaling. ${ }^{38}$

In IPF, preproendothelin-1 messenger RNA is elevated in airway epithelial cells, proliferating type II pneumocytes, endothelial cells, and inflammatory cells. ${ }^{49,50}$ Alveolar macrophages recovered by BAL from patients with IPF spontaneously express ET-1, while those from controls do not; ${ }^{31}$ in addition, plasma levels of ET-1 are significantly higher in patients with IPF than in normal controls. ${ }^{51}$

In certain diseases (e.g., connective tissue disease), endothelial cell injury may be among the earliest events, preceding inflammation or fibrosis. It has been suggested that, in these diseases, endothelial cell injury could lead to ET-1 release into the bloodstream and result in the generation of endothelin-initiated inflammatory and fibrotic cascades ${ }^{45}$ Lending some support to this hypothesis is the finding that, in subjects with mixed connective tissue disease, plasma levels of anti-endothelial cell antibodies correlate with plasma levels of ET-1.19 Whether this occurs in IPF is unknown.

Finally, while the results of a prospective, placebo-controlled study investigating the efficacy of dual endothelin receptor antagonism in SSc-ILD were negative 52 more encouraging results are available from a recently completed trial in IPF. In the international, double-blind, placebocontrolled trial (BUILD-1) of bosentan, a nonselective endothelin-receptor antagonist, analyses suggested that endothelin antagonism may be beneficial in a subgroup of patients with IPF. ${ }^{53}$ There was no difference between the placebo or bosentan groups in the primary endpoint of change from baseline in distance walked during a six-minute walk test (mean 18 meters fewer in bosentan-treated group). There was a trend favoring bosentan in the secondary combined endpoint of time to disease progression or death $(\mathrm{p}=0.1)$. Among subjects who underwent surgical lung biopsy as part of their diagnostic evaluation, bosentan was associated with a significantly decreased risk of worsening pulmonary function (relative risk 0.32 with upper limit of $95 \%$ confidence interval $=0.75$ ) and delayed time to disease progression or death $(\mathrm{p}=0.009)$. Because current practice is to perform surgical lung biopsy in a patient whose highresolution computed tomography scan does not show findings considered classic for an underlying pathologic pattern of UIP, data from BUILD-1 suggest that bosentan may be effective in subjects with atypical HRCT scans (e.g., scans that have little or no honeycombing) - in many cases, it is believed that HRCT patterns atypical for UIP correspond to earlier or less severe disease. Whatever the case, these results have provided the impetus for a second, larger, multi-center study (BUILD-3) whose results are eagerly awaited.

Other trials registered on www.clinicaltrials.gov in which investigators will test the effectiveness of endothelin antagonists in patient with IPF include the ARTEMIS trial (Randomized, Placebo-Controlled Study to Evaluate the Safety and Effectiveness of Ambrisentan in IPF) sponsored by Gilead Scienes, two studies examining the effectiveness of bosentan in patients with pulmonary hypertension in the setting of IPF (one in the U.S., and 
one in the U.K.) - both sponsored in part by Actelion Pharmaceuticals, and at least two other trials (specifics not yet made public) of endothelin antagnists in IPF.

\section{Conclusion}

Data from basic science, animal, and translational studies support the idea that the endothelin system, and ET-1 in particular, plays a role in the pathogenesis of IPF. While the initial data regarding a potential benefit of dual endothelin receptor antagonism in some patients with IPF are encouraging, additional investigation is necessary - and underway- to determine how to treat this challenging and devastating disease.

\section{REFERENCES}

1. Ortega Mateo A, de Artinano AA. Highlights on endothelins: a review. Pharmacol Res 1997;36:339_ 351. [PubMed: 9441724]

2. Kedzierski RM, Yanagisawa M. Endothelin system: the double-edged sword in health and disease. Annu Rev Pharmacol Toxicol 2001;41:851-876. [PubMed: 11264479]

3. Teder P, Noble PW. A cytokine reborn? Endothelin-1 in pulmonary inflammation and fibrosis. Am J Respir Cell Mol Biol 2000;23:7-10. [PubMed: 10873147]

4. Baynash, A.; Hammer, R.; Richardson, J.; Yanagisawa, M. Severe growth retardation and juvenile lethality in ET-2 knockout mice. Fifth International Conference on Endothelins; Kyoto, Japan. 1997.

5. Matsumoto H, Suzuki N, Onda H, Fujino M. Abundance of endothelin-3 in rat intestine, pituitary gland and brain. Biochem Biophys Res Commun 1989;164:74-80. [PubMed: 2508641]

6. Battistini B, Dussault P. Biosynthesis, distribution and metabolism of endothelins in the pulmonary system. Pulm Pharmacol Ther 1998;11:79-88. [PubMed: 9918740]

7. Ehrenreich H, Anderson RW, Fox CH, et al. Endothelins, peptides with potent vasoactive properties, are produced by human macrophages. J Exp Med 1990;172:1741-1748. [PubMed: 1701822]

8. Giaid A, Michel RP, Stewart DJ, Sheppard M, Corrin B, Hamid Q. Expression of endothelin-1 in lungs of patients with cryptogenic fibrosing alveolitis. Lancet 1993;341:1550-1554. [PubMed: 8099638]

9. Sessa WC, Kaw S, Hecker M, Vane JR. The biosynthesis of endothelin-1 by human polymorphonuclear leukocytes. Biochem Biophys Res Commun 1991;174:613-618. [PubMed: 1993057]

10. Harrison VJ, Corder R, Anggard EE, Vane JR. Evidence for vesicles that transport endothelin-1 in bovine aortic endothelial cells. J Cardiovasc Pharmacol 1993;22:S57-S60. [PubMed: 7509999]

11. Wagner OF, Christ G, Wojta J, et al. Polar secretion of endothelin-1 by cultured endothelial cells. J Biol Chem 1992;267:16066-16068. [PubMed: 1644793]

12. Arai H, Hori S, Aramori I, Ohkubo H, Nakanishi S. Cloning and expression of a cDNA encoding an endothelin receptor. Nature 1990;348:730-732. [PubMed: 2175396]

13. Sakurai T, Yanagisawa M, Takuwa Y, et al. Cloning of a cDNA encoding a non-isopeptide-selective subtype of the endothelin receptor. Nature 1990;348:732-735. [PubMed: 2175397]

14. Katwa LC, Guarda E, Weber KT. Endothelin receptors in cultured adult rat cardiac fibroblasts. Cardiovasc Res 1993;27:2125-2129. [PubMed: 8313418]

15. Masaki T, Miwa S, Sawamura T, Ninomiya H, Okamoto Y. Subcellular mechanisms of endothelin action in vascular system. Eur J Pharmacol 1999;375:133-138. [PubMed: 10443571]

16. Ergul A, Glassberg MK, Wanner A, Puett D. Characterization of endothelin receptor subtypes on airway smooth muscle cells. Exp Lung Res 1995;21:453-468. [PubMed: 7621780]

17. Goldie RG, Henry PJ, Knott PG, Self GJ, Luttmann MA, Hay DW. Endothelin-1 receptor density, distribution, and function in human isolated asthmatic airways. Am J Respir Crit Care Med 1995;152:1653-1658. [PubMed: 7582310]

18. Berti F, Rossoni G, Della Bella D, et al. Nitric oxide and prostacyclin influence coronary vasomotor tone in perfused rabbit heart and modulate endothelin-1 activity. J Cardiovasc Pharmacol 1993;22:321-326. [PubMed: 7692176] 
19. Filep JG, Bodolay E, Sipka S, Gyimesi E, Csipo I, Szegedi G. Plasma endothelin correlates with antiendothelial antibodies in patients with mixed connective tissue disease. Circulation 1995;92:2969-2974. [PubMed: 7586267]

20. Wenzel RR, Fleisch M, Shaw S, et al. Hemodynamic and coronary effects of the endothelin antagonist bosentan in patients with coronary artery disease. Circulation 1998;98:2235-2240. [PubMed: 9826308]

21. Dupuis J, Stewart DJ, Cernacek P, Gosselin G. Human pulmonary circulation is an important site for both clearance and production of endothelin-1. Circulation 1996;94:1578-1584. [PubMed: 8840847]

22. Razzaque MS, Taguchi T. Pulmonary fibrosis: cellular and molecular events. Pathol Int 2003;53:133145. [PubMed: 12608894]

23. Clark, R. Wound repair; overview and general considerations. The Molecular and Cellular Biology of Wound Repair. London: Plenum Press; 1996. p. 3-50.

24. Moulin V. Growth factors in skin wound healing. Eur J Cell Biol 1995;68:1-7. [PubMed: 8549585]

25. Greenhalgh DG. The role of growth factors in wound healing. J Trauma 1996;41:159-167. [PubMed: 8676414]

26. Badylak SF. The extracellular matrix as a scaffold for tissue reconstruction. Semin Cell Dev Biol 2002;13:377-383. [PubMed: 12324220]

27. Tomasek JJ, Gabbiani G, Hinz B, Chaponnier C, Brown RA. Myofibroblasts and mechano-regulation of connective tissue remodelling. Nat Rev Mol Cell Biol 2002;3:349-363. [PubMed: 11988769]

28. Desmouliere A. Factors influencing myofibroblast differentiation during wound healing and fibrosis. Cell Biol Int 1995;19:471-476. [PubMed: 7640660]

29. Hafstrom I, Ringertz B, Lundeberg T, Palmblad J. The effect of endothelin, neuropeptide Y, calcitonin gene-related peptide and substance P on neutrophil functions. Acta Physiol Scand 1993;148:341346. [PubMed: 7692698]

30. McMillen MA, Sumpio BE. Endothelins: polyfunctional cytokines. J Am Coll Surg 1995;180:621637. [PubMed: 7749544]

31. Shahar I, Fireman E, Topilsky M, et al. Effect of endothelin-1 on alpha-smooth muscle actin expression and on alveolar fibroblasts proliferation in interstitial lung diseases. Int $\mathbf{J}$ Immunopharmacol 1999;21:759-775. [PubMed: 10576621]

32. Peacock AJ, Dawes KE, Shock A, Gray AJ, Reeves JT, Laurent GJ. Endothelin-1 and endothelin-3 induce chemotaxis and replication of pulmonary artery fibroblasts. Am J Respir Cell Mol Biol 1992;7:492-499. [PubMed: 1419025]

33. Cambrey AD, Harrison NK, Dawes KE, et al. Increased levels of endothelin-1 in bronchoalveolar lavage fluid from patients with systemic sclerosis contribute to fibroblast mitogenic activity in vitro. Am J Respir Cell Mol Biol 1994;11:439-445. [PubMed: 7917311]

34. Dawes KE, Cambrey AD, Campa JS, et al. Changes in collagen metabolism in response to endothelin-1: evidence for fibroblast heterogeneity. Int J Biochem Cell Biol 1996;28:229-238. [PubMed: 8729009]

35. Kahaleh MB. Endothelin, an endothelial-dependent vasoconstrictor in scleroderma. Enhanced production and profibrotic action. Arthritis Rheum 1991;34:978-983. [PubMed: 1859492]

36. Schmitt-Graff A, Desmouliere A, Gabbiani G. Heterogeneity of myofibroblast phenotypic features: an example of fibroblastic cell plasticity. Virchows Arch 1994;425:3-24. [PubMed: 7921410]

37. Kulasekaren P, Scavone CA, Rogers DS, Arenberg DA, Thannickal VJ, Horowitz JC. Endothelin-1 and TGF- $\{$ beta $\}$ Independently Induce Fibroblast Resistance to Apoptosis via AKT Activation. Am J Respir Cell Mol Biol. 2009

38. Shi-Wen X, Chen Y, Denton CP, et al. Endothelin-1 promotes myofibroblast induction through the ETA receptor via a rac/phosphoinositide 3-kinase/Akt-dependent pathway and is essential for the enhanced contractile phenotype of fibrotic fibroblasts. Mol Biol Cell 2004;15:2707-2719. [PubMed: 15047866]

39. Rodriguez-Pascual F, Redondo-Horcajo M, Lamas S. Functional cooperation between Smad proteins and activator protein-1 regulates transforming growth factor-beta-mediated induction of endothelin-1 expression. Circ Res 2003;92:1288-1295. [PubMed: 12764024]

40. Hocher B, Schwarz A, Fagan KA, et al. Pulmonary fibrosis and chronic lung inflammation in ET-1 transgenic mice. Am J Respir Cell Mol Biol 2000;23:19-26. [PubMed: 10873149] 
41. Park SH, Saleh D, Giaid A, Michel RP. Increased endothelin-1 in bleomycin-induced pulmonary fibrosis and the effect of an endothelin receptor antagonist. Am J Respir Crit Care Med 1997;156:600608. [PubMed: 9279246]

42. Mutsaers SE, Marshall RP, Goldsack NR, Laurent GJ, McAnulty RJ. Effect of endothelin receptor antagonists (BQ-485, Ro 47-0203) on collagen deposition during the development of bleomycininduced pulmonary fibrosis in rats. Pulm Pharmacol Ther 1998;11:221-225. [PubMed: 9918760]

43. Selman M, King TE, Pardo A. Idiopathic pulmonary fibrosis: prevailing and evolving hypotheses about its pathogenesis and implications for therapy. Ann Intern Med 2001;134:136-151. [PubMed: 11177318]

44. Selman M, Pardo A. The epithelial/fibroblastic pathway in the pathogenesis of idiopathic pulmonary fibrosis. Am J Respir Cell Mol Biol 2003;29:S93-S97. [PubMed: 14503564]

45. Clozel M, Salloukh H. Role of endothelin in fibrosis and anti-fibrotic potential of bosentan. Ann Med 2005;37:2-12. [PubMed: 15902842]

46. Vancheeswaran R, Azam A, Black C, Dashwood MR. Localization of endothelin-1 and its binding sites in scleroderma skin. J Rheumatol 1994;21:1268-1276. [PubMed: 7525957]

47. Abraham DJ, Vancheeswaran R, Dashwood MR, et al. Increased levels of endothelin-1 and differential endothelin type A and B receptor expression in scleroderma-associated fibrotic lung disease. Am J Pathol 1997;151:831-841. [PubMed: 9284832]

48. Carpagnano GE, Kharitonov SA, Wells AU, Pantelidis P, Du Bois RM, Barnes PJ. Increased vitronectin and endothelin-1 in the breath condensate of patients with fibrosing lung disease. Respiration 2003;70:154-160. [PubMed: 12740512]

49. Giaid A, Polak JM, Gaitonde V, et al. Distribution of endothelin-like immunoreactivity and mRNA in the developing and adult human lung. Am J Respir Cell Mol Biol 1991;4:50-58. [PubMed: 1986778]

50. Saleh D, Furukawa K, Tsao MS, et al. Elevated expression of endothelin-1 and endothelin-converting enzyme-1 in idiopathic pulmonary fibrosis: possible involvement of proinflammatory cytokines. Am J Respir Cell Mol Biol 1997;16:187-193. [PubMed: 9032126]

51. Uguccioni M, Pulsatelli L, Grigolo B, et al. Endothelin-1 in idiopathic pulmonary fibrosis. J Clin Pathol 1995;48:330-334. [PubMed: 7615852]

52. Seibold JR, Black CM, Denton CP, et al. Bosentan versus placebo in interstitial lung disease secondary to systemic sclerosis: the BUILD 2 study. Proc Am Thor Soc 2006;3:A243.

53. King TE Jr, Behr J, Brown KK, et al. BUILD-1: a randomized placebo-controlled trial of bosentan in idiopathic pulmonary fibrosis. Am J Respir Crit Care Med 2008;177:75-81. [PubMed: 17901413] 


\section{Endothelin System}

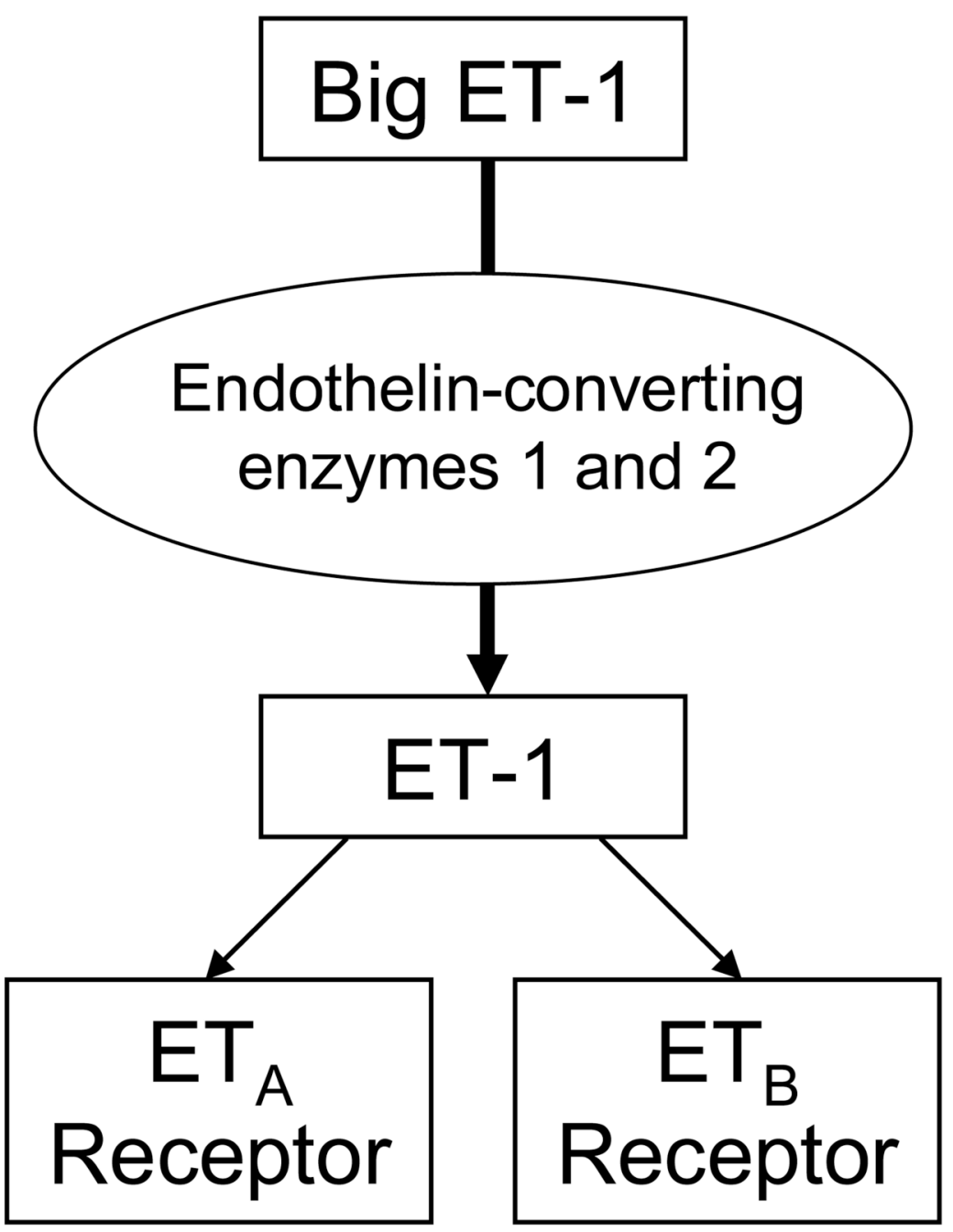

Figure 1.

The endothelin system.

$\mathrm{ET}=$ endothelin. 

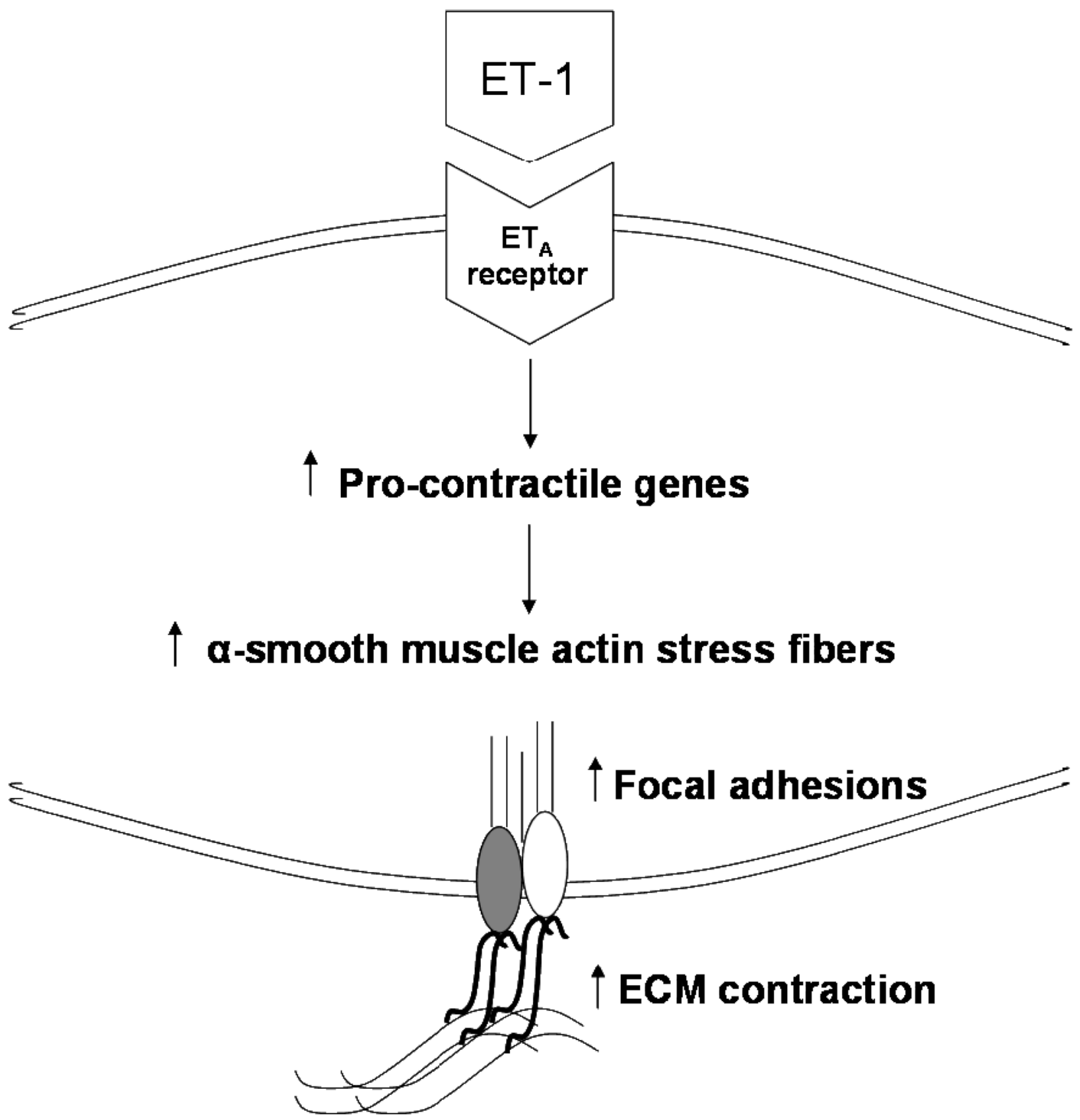

Figure 2.

How the endothelin system participates in extracellular matrix contraction. Adapted from Reference ${ }^{38}$.

$\mathrm{ET}=$ endothelin; $\mathrm{ECM}=$ extracellular matrix 